\title{
Educación Socio-Ambiental Autonomista: cambiando hábitos desde la micro-política comunitaria
}

Juliana Merçon

\section{RESUMEN \\ EDUCACIÓN SOCIO-AMBIENTAL AUTONOMISTA: CAMBIANDO HÁBITOS DESDE LA MICRO-POLÍTICA COMUNITARIA.}

Muchas de las prácticas más efectivas en la reconstrucción de nuestros hábitos socioambientales no son engendradas o mantenidas institucionalmente sino que surgen de iniciativas comunitarias. Una de estas iniciativas ocupa el centro de atención de este artículo, cuyo objetivo es analizar las motivaciones, actividades, logros y retos de un proyecto de educación socioambiental comunitario no institucional en la ciudad de Morelia, Michoacán, México: el Proyecto Jicara. Los efectos de transformación socio-ambiental en las dinámicas del grupo gestor y en la gran comunidad participante serán examinados a través de indicadores vinculados a la participación en la toma de decisiones y a la implementación de nuevas prácticas organizativas y ambientales. La instauración y fomento de procesos comunitarios de compostaje, cultivo de hortalizas, formas de movilidad no contaminantes, ferias de trueque y productos locales, intercambio de conocimientos prácticos (medicina tradicional, reparación de bicicletas, producción casera de productos de limpieza e higiene personal, etc.), creación artístico-cultural, información y discusión crítico-constructiva están entre los logros del proyecto comunitario descripto. Estos logros nos muestran como el proceso continuo de "autonomización colectiva" entrelaza dimensiones ecológicas, intelectivas y afectivas en la micro-política del cotidiano. Palabras clave: Educación socio-ambiental; autonomía; comunidad.

\section{ABSTRACT \\ AUTONOMIST SOCIO-ENVIRONMENTAL EDUCATION: CHANGING HABITS THROUGH COMMUNITARIAN MICRO-POLITICS.}

A great number of effective practices related to the reconstruction of our socio-environmental habits are not engendered or maintained by institutions but arise from community initiatives. One of these initiatives occupies the centre of our attention in this article. My objective is to analyse the motivations, activities, results and challenges of an educational community project in the city of Morelia, Michoacán, Mexico: Project Jícara. The socio-environmental effects in the managing group and in the broader community are examined through indicators related to the participation in decision-making processes and in the implementation of new Ci. Huma. e Soc. em Rev. RJ, EDUR, vol. 35, n. 2, jul / dez, p. 60-76, 2013 
organizational and environmental practices. Some of the results reached by the project are the instauration and maintenance of composting practices, agro-ecological vegetable gardens, non-polluting forms of mobility, product and service exchange systems, bioregional markets, knowledge and skill sharing (traditional medicine, bicycle workshops, homemade cleaning and personal products, etc.), cultural-artistic processes, and critical-constructive discussions. These experiences show us how the continuous process of "collective autonomisation" is one that intertwines ecological, intellectual and affective dimensions in the micro-politics of everyday life.

Key words: Socio-environmental education; autonomy; community

\section{INTRODUCCIÓN}

La rapidez con que seguimos modificando el ecosistema global es considerablemente superior al ritmo en que estamos efectuando cambios prácticos que mitiguen los efectos nocivos de nuestras actividades. Movido/as por consecuencias socio-ambientales inmediatas, y carentes de una conciencia de especie que reafirme nuestra interdependencia con otros seres y recursos naturales, hemos transformado la biosfera, causando alarmantes pérdidas de biodiversidad, cambios en el clima, en el ciclo de nutrientes y del agua, entre otros impactos (MA, 2005). En muchos casos gobiernos y empresas, sectores que ejercen gran influencia en las poblaciones, cuando no se presentan indiferentes frente a la urgencia de los problemas ambientales, buscan autopromoverse con soluciones superficiales (estilo 'placebo') que alimentan la propaganda vacía (“green-wash”) y generan aún más enajenación con respecto a las cuestiones socio-ecológicas. Frente a este escenario desafiador, iniciativas que logren disminuir nuestra huella ecológica sin comprometer la justicia social deben ser efectivamente fomentadas y multiplicadas. Un número significativo de proyectos educativos que están actualmente transformando las realidades socio-ecológicas concretas de un número creciente de personas no se vinculan a instituciones públicas o privadas sino que emergen de la auto-organización de colectividades. En este contexto se inserta el presente estudio con su objetivo de analizar las motivaciones, actividades, logros y retos de un proyecto de educación socio-ambiental comunitario no institucional realizado en la ciudad de Morelia, Michoacán, México: el Proyecto Jícara. Nuestro análisis muestra como el Proyecto Jícara actuaba como un centro de educación socioambiental, transformando hábitos referentes a la producción y uso de recursos, hábitos mentales o concepciones de mundo, y prácticas comunicativas además de formas de organización comunitaria. Los cambios promovidos por el proyecto reconfiguran aspectos diversos de las dimensiones ecológica, intelectiva y afectiva de la vida común. Estas transformaciones ambientales, epistémicas y relacionales ofrecen fuertes indicadores de la ocurrencia de relaciones educativas efectivas, fomentadoras de procesos de autonomización individual y colectiva. El énfasis dado en este estudio a los procesos de autonomización colectiva como sinónimos de 
educación socio-ambiental es justificado por razones tanto epistémicas como socio-políticas. Primeramente, es importante aclarar que identificamos la autonomización individual y colectiva con un proceso de aprendizaje continuo en el cual ocurre la comprensión activa o auto-generada de la realidad circundante. La transformación intelectiva promovida por laeducación socio-ambiental es aquí entendida principalmente como una transformación sobre las formas de comprender las relaciones socio-ecológicas. En conexión con su dimensión epistémica, a la educación como proceso autonomizador corresponde igualmente la emergencia de formas de auto-organización, reflexión, deliberación y actuación colectivas que expresan la fuerza auto-gestora de la colectividad. Enlazado concreta y virtualmente a otros proyectos e iniciativas de transformación socioecológica, el Proyecto Jícara actuaba en varias escalas: individual, grupal (colectivo gestor), comunitaria (vecindad y comunidad virtual, de participantes que no vivían cercanamente sino que se acercaban por las actividades), ciudad (a través de movimientos y eventos más amplios y de la participación activista en frentes políticas no partidarias de reivindicación y acción) y bio-región (a través de la promoción de cursos y actividades de agroecología, feria de productores locales, etc., en el entorno de Morelia). No sabemos el número exacto, pero podemos estimar que más de 300 personas distintas pasaran por la casa-proyecto a lo largo de 2010. La página-web del proyecto fornece el número total de visitas de sus 18 meses de existencia: 5,380. A través de la página, participantes distantes, que nunca estuvieron físicamente en la casa, enviaban sus preguntas sobre asuntos específicos (permacultura, bio-construcción, etc.), comunicaban sobre proyectos semejantes en otras partes de México y del mundo y dejaban sus comentarios, muchos de ellos en apoyo al proyecto. Las descripciones y comentarios aquí presentados no se pretenden exhaustivos. La motivación que subyace esta exposición es fundamentalmente la de fomentar una mayor comprensión de los procesos de educación socio-ambiental no formal y de promover transformaciones efectivas en las prácticas sociales y ambientales de comunidades urbanas.

\section{BREVE HISTORIA DE UNA INICIATIVA DE EDUCACIÓN SOCIO-AMBIENTAL COMUNITARIA NO FORMAL}

Así como muchos otros acontecimientos y procesos humanos, la historia de este proyecto que ocupará nuestra atención inicia antes de su surgimiento. Uno de sus gérmenes vino de Australia. En aquella tierra, dos miembros del proyecto participaron por varios años en actividades en el campo de la permacultura. La permacultura es un sistema de conocimientos y prácticas proyectado para integrar la vivienda y el paisaje, ahorrando materiales y produciendo menos desechos, a la vez que se conservan los recursos naturales. El diseño permacultural se destina a crear hábitats humanos sustentables y sistemas agriculturales, que imitan las relaciones 
encontradas en los patrones de la naturaleza. Los primeros proponentes de la teoría-práctica de la permacultura fueron los australianos Bill Molison (1988) y David Holmgren (2002). Además de dedicarse a actividades permaculturales, servieron también de inspiración sesiones de intercambio de ideas y saberes prácticos en la casa-proyecto TurnStyle en Brisbane. Las experiencias en este último espacio fueron decisivas para la creación del Proyecto Jícara en México. TurnStyle era una casa abierta a la comunidad, donde había un huerto de traspatio, un taller para reparación de bicicletas, muestras y discusiones de documentales, talleres de arte, organización activista, etc. La casa-proyecto era auto-gestionada por un colectivo de amigo/as que allá vivía. Llegando a México, tres criterios guiaron la búsqueda de la casa en la cual viviríamos: el tamaño de la casa (porque queríamos compartirla con otras 2, 3 o 4 personas), la disponibilidad de área verde (porque queríamos seguir cultivando hortalizas y tener árboles frutales), y la cercanía a nuestros lugares de estudio y trabajo (porque nos movemos en bicicleta). Encontramos una gran casa construida con adobe y otros materiales y técnicas tradicionales, con colecta de agua de lluvia y área verde al costado y en frente, que además no estaba muy distante de los puntos a los cuales nos movíamos diariamente. La colonia urbana en la cual se ubica la casa congrega distintas clases sociales, mayoritariamente media-baja, con casas populares. No está en el centro de la ciudad de Morelia, sino que próxima a una de las salidas de la ciudad. Para llegar a personas interesadas en vivir y construir colectivamente una forma de vida más sustentable, con dimensiones de abertura a la comunidad, los dos miembros recién llegados a Morelia enviamos mensajes a las listas de las instituciones donde estudiábamos/trabajábamos y distribuimos carteles en los cuales describíamos la casa y nuestras intenciones. Invitábamos de esta forma a que interesado/as vinieran a conocer a la casa, a nosotros/as y a nuestros objetivos. Formamos así un colectivo de seis personas dispuestas a desarrollar diversas actividades comunitarias desde nuestra casa-proyecto.

\section{EL PROYECTO JÍCARA EN ACCIÓN}

Las actividades ofrecidas a la comunidad por el Proyecto Jícara eran todas gratuitas, con excepción de algunos talleres en que eran solicitadas contribuciones para cubrir costos de materiales (como en el caso de los talleres de comida vegetariana) o de traslado (como en el caso de una señora que ofreció un taller de huerto medicinal). Consensuadas y organizadas entre los seis miembros gestores, las actividades tenían los objetivos de promover prácticas socio-ambientales más sustentables, generadoras de mayor cuidado y responsabilidad frente a los recursos naturales, y mayor solidaridad y auto-determinación colectiva con respecto a los lazos comunitarios. Eran cuatro las principales actividades desarrolladas por el Proyecto Jícara: 


\section{Chamb(a)prendizaje en el Huerto Orgánico}

Las tardes de los domingos eran destinadas a trabajos en el huerto comunitario. Las tareas para cada tarde eran predeterminadas por el colectivo gestor. A los miembros de la comunidad que se integraban para participar en la 'chamb(a)prendizaje' eran comunicadas las distintas actividades del día. Cada persona elegía en cual quería participar y era acompañada por al menos uno de los miembros gestores, que le explicaba las razones, objetivos y métodos usados, al paso que implementaban juntas las acciones descritas. Se trataba fundamentalmente de un espacio compartido de educación socio-ecológica práctica y significativa, de experimentación activa de los nuevos conocimientos, actitudes y acciones. Las actividades desarrolladas en el huerto incluían la organización de espacios, preparación de camas de cultivo, siembra, cosecha, preparación y tamización de la composta, construcción de estructuras con bambú y materiales reciclados (rejas, gallinero, lombricompostero, etc.), donación e intercambio de semillas, plántulas y verduras. El uso del espacio urbano para la realización de un huerto orgánico comunitario recibió la aprobación previa de lo/ as vecino/as, así como el apoyo activo de vario/as de ello/as. Además de enseñar y aprender mutuamente sobre formas específicas de cultivo en la ciudad, la manutención de este huerto comunitario mostraba con su ejemplo el potencial existente en el contexto urbano para la producción local de comida y la gestión comunitaria. Se estima que más de 70 personas contribuyeron activamente en esta actividad de 'chamb(a)prendizaje' a lo largo de un año. A través de la página-web de la casa y de su lista de participantes eran también promovidas acciones colectivas (tequios) con objetivos de reforestación en la ciudad (utilizando especialmente plántulas de frutales) y de iniciar otros huertos orgánicos comunitarios.

\section{Cine-Documental sobre cuestiones socio-ambientales}

En los domingos por la noche, después del trabajo colectivo en el huerto, eran proyectados documentales los cuales eran seguidos de una discusión entre lo/as espectadore/as. Las temáticas trataban en su mayoría de problemas socio-ambientales. Fueron realizados varios ciclos o muestras con temas específicos, como por ejemplo: Cambios sociales en Latinoamérica; Construyendo alternativas; Turismo: impactos y alternativas; Mujeres: logros y desafíos; Bici-Cine; entre otros. Cada ciclo de documentales era compuesto por una pequeña serie de películas sobre un mismo tema. Nuestro objetivo era tanto profundizar el conocimiento y la discusión sobre cuestiones específicas como permitir la presentación de distintas miradas sobre un mismo tema. La plática abierta después del documental además de incentivar el planteamiento de distintas posiciones teóricas frente a las cuestiones presentadas, muchas veces generaba también el intercambio de informaciones sobre iniciativas inspiradoras y acciones que podemos tomar localmente, empoderando a lo/as participantes. Se estima que más de 200 personas participaron en las sesiones de Cine-Documental promovidas en la casa a lo largo del año. 


\section{Talleres: compartiendo nuestros saberes prácticos}

Aproximadamente una vez al mes eran realizados talleres a través de los cuales eran compartidos diversos saberes prácticos. Lo/as talleristas eran personas de la bio-región invitadas por sus conocimientos en un campo específico o voluntario/as que proponían compartir sus saberes prácticos. Fueron realizados varios talleres sobre temas socio-ambientales diversos, como por ejemplo: Compostaje urbana; reparación de bicicletas; plantas medicinales; cocina vegetariana; producción casera de materiales de limpieza; bio-construcción con barro; entre otros. Los talleres ocurrían en los domingos por la tarde y eran seguidos de documentales sobre el tema abordado. Personas que no participaban en el taller podían llegar por la noche para asistir al documental. Entre las distintas actividades ofrecidas por la casa, la organización de talleres fue la que logró congregar el mayor número de personas. Entre 40 y 50 personas participaron, por ejemplo, en los talleres sobre plantas medicinales y reparación de bicicletas. Considerando el espacio disponible, el hecho de que todo el trabajo era voluntario y práctico, exigiendo la participación activa de lo/as asistentes, con 50 personas alcanzábamos el cupo máximo. En el tercer taller con mayor participación se propuso compartir conocimientos y prácticas sobre bio-construcción con barro. En este caso específico el taller ocurrió durante todo un fin de semana en el rancho de un amigo colaborador del Proyecto Jícara. Treinta participantes aprendieron técnicas distintas de construcción de paredes con barro (adobe, pared francesa, paja encofrada, malla cubierta, etc.) mientras ayudaban efectivamente a construir una casa. En su totalidad, estimamos que más de 200 personas participaron activamente en los talleres promovidos por el Proyecto Jícara. 4. Trueque Solidario: intercambio de productos y servicios en la comunidad Cuando la casa ya se había tornado un polo conocido por centenas de personas en la ciudad, fue propuesta la creación de una red de trueque de productos y servicios. En una reunión abierta, fueron discutidas las formas de participación y procedimientos, y creado un nombre para la red: Cambalache Solidario. Los deseos colectivos que movieron la creación de esta red de trueque eran: vivir medios alternos - no centrados en el dinero - para conseguir y ofrecer servicios/objetos; cubrir necesidades sin el uso del dinero; descubrir que dependemos menos del comercio convencional e impersonal que lo suponíamos; fortalecer la economía local; compartir habilidades y productos; conocer personas con intereses comunes; ayudar y ser ayudado/a; crear lazos comunitarios. Luego se inició un directorio en el cual lo/as participantes del Trueque incluían los productos y servicios que ofrecían a la comunidad así como los artículos y servicios que buscaban. El acceso al directorio ocurría a través de la página-web del Proyecto. Los productos y servicios ofertados y buscados entre los miembros que participaban en el directorio nos permiten tener un panorama de las habilidades y recursos disponibles en la comunidad local. Agrupados por categorías, estos productos y servicios están relacionados a: Huerto orgánico (conocimientos, prácticas y materiales); Comida casera (mermelada, pan, repostería, etc.); Lenguas (clases, redacción, revisión, etc.); Libros, CDs, DVDs; Terapia y 
Educación Somática (yoga, reikki, Feldenkrais, danza, etc.); Medicina Tradicional (cursos, asesorías, etc.); Manualidades (costura, crochet, artesanía, libretas, etc.); Artículos para casa y personales (muebles, computadora, celular, etc.); Cuidado de niños (cuentacuentos, ayuda con tareas, etc.); Juegos y deportes (ajedrez, esgrima, juegos autóctonos, natación, karate, etc.); Conversaciones (sobre sustentabilidad, astronomía, filosofía, lectura de libros, etc); Animales (donación, asesoría en etología canina, cuidado de mascotas, etc.); Bicicletas (arreglos y partes); Otros (asesoría legal, instalación de Linux, ideas para reuso de plástico y vidrio, etc.). Miembros de la casa y otro/as participantes del Proyecto Jícara organizaran dos Ferias de Trueque. La primera fue realizada en el patio de la casa-proyecto y tuvo la participación de aproximadamente 30 personas. Con el objetivo de ampliar la iniciativa, alguno/as vecino/as propusieron la realización de la feria siguiente en el parque de la colonia. Una pequeña comisión organizadora fue formada con vecino/as y miembros de la casa-proyecto. Participaron de la segunda feria aproximadamente 60 personas, entre vecino/as de la colonia y visitantes de otras localidades. Lo/as participantes llevaban objetos y productos caseros para intercambio, además de carteles en los cuales anunciaban los servicios que ofrecen a la comunidad. Como regla consensuada antes de la feria, no se utilizaba dinero en ningún caso, y la noción de justicia a guiar los intercambios era acordada entre los miembros participantes en la transacción. A más de las actividades realizadas en la casa y en su colonia, el Proyecto Jícara contribuía activamente a otras iniciativas socio-ecológicas urbanas y en la bio-región. La organización ciudadana de Defensa del Área Natural Protegida de la Loma de Santa María era apoyada por la casa-proyecto en sus acciones en resistencia a la construcción de una carretera que ponía en riesgo la única reserva de bosques en Morelia. El grupo de teatro ecológico Ecoludens utilizaba la casaproyecto regularmente para sus ensayos y estrenó la lectura dramatizada de su obra 'Autos, Res y Excusados' en la casa. Uno de los colectivos asociados a La Otra Campaña de Morelia encontraba en la casa un espacio para reuniones y elaboración de informes en medios alternativos. El proyecto promovía la movilidad en bicicleta también a través de la participación de sus miembros en el movimiento Masa Crítica. El proyecto apoyaba directamente a la producción local de alimentos y otros productos a través del tianguis orgánico, de eco-tiendas y, principalmente, a través de la Feria Alternativa la cual ayudó a crear y promover en el pueblo vecino de Arocutín. Cursos de Permacultura realizados cercanamente, en la Granja Tierramor en Erongarícuaro, contaban con talleres de Ecología Urbana ofrecidos por miembros gestores del Proyecto Jícara. 


\section{TRANSFORMANDO LA REALIDAD}

Distintas teorías del aprendizaje proveen distintas maneras de comprender este fundamental evento humano. En Occidente, tres perspectivas principales han agrupado diferentes autores y concepciones educativas o socio-psicológicas sobre el acto de aprender: 1. la comportamentalista, con mayor impacto en países anglosajones y representada por autores como Skinner (1938) y Watson (1913); 2. la cognitivista, con énfasis en los procesos cognitivos (PIAGET, 1926), y que dió origen a estudios acerca del desarrollo moral (KOHLBERG, 1981); 3. la socio-cultural, representada por Vygotsky (1926) y consonante en su base teórica con la propuesta educativopolítica de Paulo Freire (1970). Si desconsideramos momentáneamente los varios puntos de incompatibilidad entre estas teorías, desde una mirada más abarcadora es posible destacar lo cuanto los elementos enfatizados por cada teoría son, de hecho, complementarios e interdependientes: comportamiento-pensamiento-interacción social. En las líneas que siguen tejeré comentarios sobre estas tres principales dimensiones educativas que actuaban interdependientemente en el Proyecto Jícara.La dimensión ecológica: cambiando hábitos referentes a la producción y uso de recursos (alimentación, vivienda, energía y movilidad)La experiencia activa y colectiva tejida por la postura del 'aprender haciendo' que impulsaba todo el proyecto contribuyó a diversos cambios significativos en los hábitos de sus participantes. Aunque sea difícil evaluar los efectos sobre los participantes no-gestores del proyecto, es posible inferir desde los hábitos implementados en la casa que estos servían de inspiración transformadora a otro/as por tres razones por lo menos: 1 . por se tratar de un hogar, las distintas personas que participaban en las actividades allá promovidas vivían un ejemplo práctico de pequeños y grandes cambios que ellas mismas podían implementar en sus casas; 2. además de no se tratar de un espacio institucional, los lazos establecidos con los miembros de la casa eran igualmente informales, permitiendo consultas, pláticas y reflexiones con efectos vivenciales significativos; 3 . la casa era un espacio al cual los miembros de la comunidad podían regresar siempre y cuando querían, habiendo una abertura también informal y cercana, creadora de vínculos afectivos transformadores. El cambio más notable en los hábitos cotidianos de los miembros-gestores y de otro/as miembros de la comunidad quizás se refiera a la inserción de una esfera de producción básica en sus vidas. Lo/as 6 miembros-gestores compartían tareas diarias de mantenimiento de las gallinas, de macetas con hierbas y del huerto con hortalizas y frutales en frente a la casa. El reajuste de los horarios y el intento de dividir esfuerzos para que todo/as pudiesen cumplir con sus compromisos de trabajo y estudio sin mayores sacrificios ocurrieron desde el principio, siendo siempre susceptible a cambios al paso que el sistema incluía nuevas demandas o se reconfiguraba por modificaciones en la rutina. Los saberes asociados a la producción de comida en el contexto urbano, la valoración de este proceso, la auto-confianza y resiliencia comunitarias están entre los principales efectos educativos de esta dimensión del proyecto. 
Considerando que la cantidad de comida producida por la casa era inferior a la que es necesaria para nuestro sustento diario, nuestros hábitos colectivos de consumo incluían también, por orden de prioridad, la compra de productos orgánicos locales, la adquisición de granos y productos frescos (ni siempre orgánicos) en los tianguis cercanos. Evitábamos consumir productos enlatados, con muchos empaques y conservadores, así como productos vendidos por grandes cadenas de supermercados o de marcas comprometidas por cuestiones sociales y/o ecológicas. Se trataba de una casa con bajísimo consumo de carne (varios miembros eran vegetariano/as) - con la proteína animal siendo fornecida por huevos frescos de nuestras gallinas, yogurt casero, queso y leche. En los talleres de Cocina Vegetariana eran también discutidos problemas sociales (explotación del trabajo, concentración de capital, etc.), ecológicos (uso de agroquímicos, transporte a largas distancias, uso de recursos en la producción de la carne, etc.) y de salud personal (efecto de conservadores, demasiada grasa, sal, azúcar, productos refinados, etc.) asociados a la producción y consumo de la comida. El aprovechamiento consciente de los recursos espaciales, de sustento básico y energéticos disponibles operaba igualmente cambios individuales y colectivos importantes. A empezar por el uso del espacio, como se trataba de una casa grande, con 5 recámaras, vivíamos vario/as en la misma casa (los números fluctuaron la mayor parte del tiempo entre 6 y 7 personas) y usábamos productivamente el patio (con macetas y como local de encuentro), el área verde interno (con gallinas) y el área verde público en frente (con el huerto comunitario). El agua, uno de los recursos más esenciales a la vida, era utilizada conscientemente. Lo/as integrantes de la casa colectaban con cubetas el agua de la ducha y de la llave en el baño para reutilización en el excusado y para lavaje de ropas. El agua de la lluvia era recanalizada a un gran aljibe en el patio y el agua gris de la cocina y de la lavadora era utilizada para regar los árboles frutales en el huerto. Buscábamos reducir el consumo de gas y electricidad, aunque el hecho de que cocinábamos diariamente y de que la casa de adobe era obscura en su interior representaba retos considerables. Muchos de estos hábitos eran objeto de discusión colectiva entre los miembros-gestores y otro/as participantes, promoviendo nuevos cambios rumbo a la utilización más atenta, generando menos desperdicio y más reuso. A pesar de la casa-proyecto no estar ubicada en el centro o muy cercanamente a los sitios de trabajo y estudio de sus integrantes-gestores, ningún miembro poseía automóvil particular. Todo/as nos movíamos diariamente en bicicleta o transporte público. Además del ejemplo vivencial fornecido por los miembros del Colectivo Jícara, tres actividades principales promovieron el uso frecuente de la bicicleta en la comunidad: el taller de reparación de bicicletas, en el cual por toda una tarde de actividades fueron intercambiados saberes prácticos sobre como arreglarlas y mantenerlas en buen estado; el Ciclo de Documentales Bici-Cine, a través del cual a lo largo de un mes asistimos a distintos documentales sobre planeación urbana sustentabley uso de bicicletas, movimientos como Masa Crítica, etc.; y las discusiones sobre movilidad urbana promovidas entre los participantes al final de los documentales. Un total de más de 100 personas participaron en estas tres actividades. 
Los diversos cambios en las prácticas ecológicas urbanas promovidos por el Proyecto Jícara ocurrían en distintas escalas y de forma interrelacionada. La sugerencia de un individuo era evaluada y puesta en práctica colectivamente si nos mostraba una forma más consciente y razonable de uso de recursos y/o producción de alimentos. Estos cambios eran compartidos vivencialmente con los miembros de la comunidad que participaban en las actividades de la casa. En algunos casos, la necesidad interna de modificar los hábitos ecológicos de cuidado del espacio daba origen a talleres específicos, como fue el caso del taller sobre producción casera de materiales de limpieza, al cual invitamos una amiga a compartir sus saberes prácticos para la preparación de productos no comerciales, menos agresivos al medio ambiente y a la salud humana. Del individual o del colectivo cercano a la comunidad más amplia, los cambios en nuestros hábitos ecológicos acompañaban la expansión de nuestra consciencia y el deseo colectivo de vivir de maneras más solidarias y sustentables.

\section{La dimensión intelectiva: cambiando hábitos mentales y visiones de mundo a través de la criticidad-} constructiva

No todo cambio posee como requisito una comprensión crítica y compleja de los elementos que componen nuestra acción. Muchas veces nuestros hábitos socio-ecológicos son modificados a través de la imitación de las acciones de otros sin que comprendamos los mecanismos sociales y ambientales que sostenemos con nuestros hábitos. El cambio que genera formas de cuidado ambiental y social más vigorosas sigue siendo positivo aun cuando desprovisto de una consciencia más amplia y crítica. Este es el caso, por ejemplo, de muchos 'consumidores verdes' que compran en eco-tiendas en boga por cuestiones de status (evidenciando un mayor 'capital cultural') o por reflexiones limitadas a su salud personal. A pesar de positivo por implicar una modificación de los hábitos en algún nivel, el cambio socio-ecológico careciente de una comprensión crítica más abarcadora tal vez no permita que pensamiento y acción inter-conecten distintas esferas de la vida (privada y pública), distintos hábitos (producción, consumo y tratamiento dado a residuos, locomoción, etc.) y diferentes procesos socio-ambientales a ellos asociados. Si cualquier cambio positivo es celebrado, aún más serán aquellos que acompañan el entendimiento complejo y crítico, atento a las conexiones entre los distintos campos de la vida individual y comunitaria. Ello porque la comprensión activa promueve no solamente la adopción o repetición de acciones ya efectuadas por otros como también la instauración de nuevos hábitosy formas de relación conel medio-ambienteyla comunidad humana. El cambio de hábitos mentales y de nuestra visión de mundo es una tarea siempre inconclusa, susceptible a mejoramientos contantes. La participación activa en procesos colectivos que promueven la crítica de la realidad actual y la construcción de alternativas ejecutables corresponde a un proceso de extrema importancia educativa. La colectividad provee una diversidad de recursos intelectivos (distintas experiencias, saberes, opiniones, ideales, etc.), de 
estilos comunicacionales y maneras de concretar acciones que tiene el potencial de enriquecer el pensamiento de los individuos vinculados aunque estos no participen activamente en las discusiones y otras prácticas. En adición a la exposición a una multiplicidad de visiones críticas, la participación activa promovida por el proyecto tenía como efecto la consideración crítica de los propios pensamientos y de la realidad circundante, entre otros. Conscientemente orientada hacia diálogos horizontales entre participantes de distintos géneros, edades, clases sociales, etnias y nacionalidades, las prácticas discursivas del Proyecto Jícara poseían como objetivo la ampliación del pensamiento crítico y constructivo de individuos y de la colectividad. Este objetivo, aunque nunca alcanzado de forma absoluta, era parcialmente realizado en pláticas tanto informales como organizadas entre los miembros-gestores y otros miembros de la comunidad. El ejercicio del pensamiento propio con otro/as era incentivado y concretado, por ejemplo, en reuniones para discutir las dinámicas en curso en la casa (actividades, inconformidades, tareas, formas tácitas y/o explícitas de ejercicio de poder, etc.) y en las discusiones con participantes externos, principalmente, después de los documentales exhibidos los domingos en la noche. En un clima de informalidad, se abría la discusión a las impresiones de lo/as espectadore/as e íbamos conjuntamente, sin una coordinación pre-determinada, conociendo a las distintas opiniones, haciéndonos preguntas, y ampliando nuestras visiones críticas y creativas. El ejercicio del pensamiento crítico frente a la realidad socio-ecológica en la cual estamos inmerso/as configura una dimensión esencial al cambio significativo. No tomar la realidad como auto-evidente, necesaria o inmutable, sino que comprender críticamente las razones histórico-filosóficas, culturales, políticas y económicas que la mantienen nos permite afirmar posicionamientos menos superficiales y menos sujetos a influencias poco o no razonables. Además de promover formas activas de resistencia al modelo de relación socio-ecológica predominante, la criticidad propulsa por la vía de la lucidez inconforme la creación de alternativas. En este sentido, en asociación con la práctica dialógica crítica, el proyecto buscaba también explorar el campo de posibilidades constructivas que el rechazo a las formas convencionales de sociabilidad y relación ambiental instauraba. En este sentido, muchas acciones emprendidas individual y colectivamente a lo largo del año considerado en este breve análisis surgieron de diálogos colectivos críticocreativos con miembros participantes del proyecto. Este fue el caso, por ejemplo, de diversos talleres, de la formación de la red de trueque, de los trasplantes de frutales en áreas públicas, etc. Ladimensiónafectiva:cambiandohábitoscomunicacionales, relacionalesydeorganizacióncomunitaria La transformación de nuestro pensamiento y acción es fomentada por lazos afectivos muchas veces invisibles. La inspiración que recibimos al ver un individuo o un grupo actuando de maneras admirables posee una fuerza más significativa que aquella transmitida por palabras en un contexto inerte o de cuerpos pasivos. Quizá no sea exagerado decir que la información vivida como experiencia práctica, como relación dinámica y efecto en la realidad genera cambios más globales y profundos. Atento/as a esta dimensión fundamental en cualquier iniciativa de 
educación socio-ambiental, buscábamos cuidar el afecto que nutríamos entre lo/as participantes. La comunicación respetuosa, abierta y honesta era uno de los horizontes afectivos rumbo al cual caminábamos. El convivio cercano entre los miembros del grupo-gestor ni siempre era armonioso, generando la necesidad colectiva de repensar las relaciones, la sensibilidad y el cuidado que nos mantenía unido/as, promoviendo o no los lazos de amistad. Dinámicas que fomentaban la participación horizontal y la expresión sincera sobre distintos aspectos de la convivencia, de las tareas diarias y de las actividades del proyecto comunitario eran realizadas con el propósito de reflexionar colectivamente sobre los retos que nos confrontaban y rumbos constructivos a ser experimentados. De las reuniones entre lo/as integrantes de la casa, emergieron posturas más atentas y cuidadosas con respecto a nuestras relaciones, además de distintos modelos de sistematización de las tareas de la casa y de organización de las actividades del proyecto. En una ocasión se decidió, por ejemplo, que habría una rotación en la coordinación de las diferentes actividades del proyecto, con equipos de apoyo para su realización. El intercambio afectivo y solidario con mucho/as participantes de la comunidad ocurría en el curso de las actividades y también, muy especialmente, en los momentos en que nos dedicábamos a cocinar y comer junto/as. Todos los domingos entre la chamba en el huerto o el taller y el cine-documental preparábamos una cena entre todo/as que habíamos compartido la actividad del día. Con la cocina y el comedor llenos celebrábamos la buena comida, la fuerza colectiva y la amistad. Por este clima informal y cercano, integrador de diferencias e ideales que se concretaban en la comunidad, la casa se transformó en un pequeño pero también importante polo de encuentro para organización y acción comunitaria.

\section{LA EDUCACIÓN SOCIO-AMBIENTAL COMO UN PROCESO DE AUTONOMIZACIÓN COLECTIVA}

Considerando lo discutido anteriormente podemos afirmar que una relación educativa significativa es aquella que conlleva a cambios socio-ambientales a través de la actuación conjunta de las dimensiones práctica, intelectiva y afectiva. Desde las experiencias promovidas por el Proyecto Jícara estamos convencido/as de que una relación educativa comunitaria efectiva se expresa a través de procesos de autonomización colectiva. ¿Por qué sería la autonomización un rasgo esencial del proceso de educación socio-ambiental comunitaria? La autonomización definida como proceso (y no la 'autonomía' como punto de total realización en el cual se alcanza por completo la gestión comunitaria independiente) es una característica fundamental de la educación socio-ambiental por dos razones principales: una de orden epistémica y la otra de orden socio-política. 
Si los conocimientos teórico-críticos y práctico-constructivos compartidos no son incorporados y reconfigurados con sentidos propios por los individuos, podemos decir que la interacción educativa no está generando resultados significativos. Desde una perspectiva epistémica, la educación o el aprendizaje efectivo corresponde al proceso de asimilación y reconstrucción de las estructuras y contenidos cognitivos, a través de la comprensión activa o auto-generada de la realidad circundante. Educarse con otrolas significa, desde su sentido epistémico, actuar sobre y con el propio pensamiento en contextos en los cuales potencializamos el pensar propio a través de la participación activa de otro/as interlocutore/as. En suma, la transformación intelectiva promovida por la educación socio-ambiental es primordialmente una transformación sobre las formas de comprender la realidad a través de la incitación al ejercicio colectivo del pensamiento autónomo. Desde una perspectiva socio-política, la educación socio-ambiental engloba procesos de autonomización colectiva porque en correspondencia con el uso del pensar propio son generadas formas de auto-organización, reflexión, deliberación y actuación colectiva que expresan la fuerza auto-gestora de la colectividad. Sin la creación de sus propios objetivos y formas de funcionamiento colectivo, sin la experimentación colectiva que busca conectar sus propias ideas a la acción comunitaria, la experiencia educativa se reduce a un intento fracasado, donde la indiferencia, la dependencia o la reproducción de modelos externos prevalecen sobre la emancipación sociopolítica. En este sentido, la educación socio-ambiental comunitaria implica la promoción de condiciones que posibiliten a los miembros de la colectividad organizarse alrededor de sus propios objetivos e ideales, elaborando e implementando los medios para las acciones que transformarán la comunidad. En muchos casos, la educación socio-ambiental comunitaria corresponde precisamente al proceso a través del cual será creada la comunidad en su sentido estricto. Los lazos socio-políticos, o sea, la articulación colectiva de fuerzas para pensar y actuar, muchas veces son activados y resultan de la intervención educativa como proceso de autonomización colectiva. ¿Cuáles habrán sido algunos de los momentos en el proceso de autonomización colectiva del Proyecto Jícara? Los momentos comentados a continuación no representan etapas necesariamente sucesivas en una línea progresiva o ascendiente. Algunos podían ocurrir de forma simultánea o en una secuencia inversa a la que se presenta en seguida.

\section{Ideales Compartidos: construyendo una base común}

No solamente al inicio sino también a lo largo de la existencia del proyecto colectivo (cuando nuevos miembros se incorporaban al grupo gestor y/o fuertes diferencias con respecto a los rumbos de las acciones se hacían presentes) fue importante revisar y expresar los ideales (deseos, planes, metas) que motivaban nuestras prácticas individuales y grupales. Al explicitar los rasgos comunes que nos movían podíamos, además de reiterar lo que nos 
unía, conjeturar sobre los pasos siguientes a concretar conjuntamente. La importancia de partir de una base común simbólica y práctica se refleja en la confianza, apoyo recíproco y motivación compartida para actuar de maneras cada vez más solidarias y sustentables.

\section{Co-educación: la mutualidad como lazo de aprendizaje}

El reconocimiento sincero de que somos todo/as aprendices en un proceso interminable de cambios hacia una vida más solidaria y sustentable está en la base de la mutualidad educativa. Todo/as tenemos algo a enseńar y mucho a aprender. Desde lo/as expertos en cuestiones ecológicas o sociales a lo/as señores y señoras de la vecindad, niños y jóvenes, siempre hay algo a aportar que contribuye al proceso de auto-reflexión, crecimiento comunitario y cambio de las prácticas ambientales. La interacción co-educativa es primordialmente autonomizadora en el sentido de que valora los saberes que todo/as traemos y fomenta su intercambio a través de la auto-confianza para pensar y comunicarse. En el grupo autogestor y entre los miembros de la comunidad, la co-educación se afirmaba como un momento crucial de generación de vínculos fortalecedores del aprendizaje transformador.

\section{Deliberación y Actuación Colectivas: transformando hábitos sociales y ecológicos}

La autonomización colectiva muestra su faz más visible en la actuación socio-a mbiental que deriva de los procesos de discusión, reflexión y deliberación comunitaria. La acción resultante de estos procesos socio-políticos demuestra un verdadero cambio en la estructuración individualista de la vida común y, en el caso de este y de otros proyectos de educación ambiental, repercuten también en la forma como actuamos con los recursos naturales de los cuales depende nuestra existencia. A través de reuniones o discusiones informales los diversos puntos pre-establecidos o que emergían espontáneamente eran tratados a fin de redefinir las prácticas micro y macro-comunitarias.

\section{Evaluación Colectiva: ¿Qué nos preocupa? ¿Qué cambios implementar? ¿Cómo?}

El momento de evaluación colectiva involucra el examen de la práctica y de su sistema intelectivo subyacente. Las dificultades, problemas y retos que surgen en el transcurrir de la vida común son analizados para que sean formuladas propuestas y efectuados nuevos intentos. La comunicación honesta, receptiva, atenta, así como una actitud que nos pone con mayor disposición a vivir cambios constructivos participan en este proceso como componentes esenciales. En el Proyecto Jícara los momentos de auto-evaluación colectiva eran decisivos para la reafirmación de los lazos humanos a través de la escucha atenta, del pensamiento activo y de su abertura al cambio. La exploración de las distintas impresiones, opiniones y sensaciones nos proveía los elementos intelectivo-afectivos para diseñar las próximas acciones. 


\section{SIGUIENDO ADELANTE}

Los logros vividos a través de este proyecto urbano de auto-gestión colectiva se extienden por distintos campos de la vida común. Según lo destacado anteriormente, cambios en los hábitos referentes a la producción y uso de recursos, en hábitos mentales o en concepciones de mundo, y en la comunicación y forma de organización comunitaria demuestran la reconfiguración socio-política de las dimensiones ecológica, intelectiva y afectiva de nuestra co-existencia. Estas transformaciones prácticas, epistémicas y afectivas ofrecen fuertes indicadores de la ocurrencia de relacioneseducativas efectivas, fomentadoras de procesos deautonomización individualycolectiva. Un logro directamente asociado a las particularidades del Proyecto Jícara corresponde al hecho de haber demostrado la ejecutabilidad de iniciativas comunitarias que poseen como centro físico-relacional el hogar urbano. Es importante resaltar que su organización no institucional, su no filiación a ningún partido político o dogma ideológico, y su fuerte rasgo no comercial no actuaron como impedimentos para su realización sino que alimentaron su fuerza cohesiva, así como la extensión e intensidad de sus impactos ecológicos y comunitarios. El carácter no formal del proyecto denotaba algunos retos específicos así como algunos beneficios, principalmente en lo que concierne las dinámicas de autogestión. En la tabla abajo (Tabla 1.) son presentadas algunas de las desventajas y ventajas de este tipo de proyecto urbano de educación socio-ambiental no formal.

Tabla 1. Desventajas y ventajas asociadas a proyectos de educación socio-ambiental no formal.

\begin{tabular}{|l|l|}
\hline \multicolumn{1}{|c|}{$\begin{array}{c}\text { Desventajas de proyectos de educación socio- } \\
\text { ambiental no formal }\end{array}$} & \multicolumn{1}{c|}{$\begin{array}{c}\text { Ventajas de proyectos de } \\
\text { educación socio-ambiental no } \\
\text { formal }\end{array}$} \\
\hline Falta de apoyo financiero institucional & $\begin{array}{l}\text { Autonomía para generar y aplicar } \\
\text { recursos sin atender a intereses } \\
\text { externos }\end{array}$ \\
\hline $\begin{array}{l}\text { Estructuración social no está pre-establecida como } \\
\text { en la escuela (sentido de colectividad es algo a ser } \\
\text { creado) }\end{array}$ & $\begin{array}{l}\text { Los procesos de auto-gestión } \\
\text { son activados a través de } \\
\text { contribuciones concretas y el } \\
\text { sentido de comunidad es generado } \\
\text { sin modelos preexistentes }\end{array}$ \\
\hline $\begin{array}{l}\text { Alcance limitado por falta de divulgación de masa o } \\
\text { en amplia escala }\end{array}$ & $\begin{array}{l}\text { Enfasis en la comunicación } \\
\text { directa y medios autónomos } \\
\text { para la divulgación (carteles } \\
\text { de fabricación casera, volantes, } \\
\text { internet, etc.) }\end{array}$ \\
\hline $\begin{array}{l}\text { Ausencia de mecanismos instituidos que determinen } \\
\text { tareas específicas a gestores }\end{array}$ & $\begin{array}{l}\text { Fomento al ejercicio de } \\
\text { habilidades múltiples por } \\
\text { cada miembro gestor y por } \\
\text { participantes }\end{array}$ \\
\hline
\end{tabular}


A través del Proyecto Jícara otros agrupamientos eran apoyados, sirviendo como un seguimiento de otras iniciativas, además de conformar un polo en el cual participaban otros proyectos socio-ambientales (masa crítica, feria alternativa de productores locales, contactos y cursos de permacultura, bio-construcción, eco-tiendas y tianguis orgánico, etc.). La fuerza de este proyecto de educación socio-ambiental nutría y era nutrida por redes sociales cercanas e indirectas: así como actuaba para iniciar nuevas redes de intercambio de saberes y cambio de las prácticas socioecológicas urbanas, el proyecto se beneficiaba de la participación de otras iniciativas y de sus redes. La importancia de multiplicar experiencias comunitarias de educación socio-ambiental no formal es inestimable. Al no esperar (in)cómodamente que los gobiernos o empresarios resuelvan los problemas que perpetuán cadenas de depredación social y a mbiental, comunidades urbanas pueden tornarse actores directos en la reversión de estos procesos destructivos y en la construcción de alternativas. En el centro de estos cambios socio-ambientales se afirman los lazos de educación mutua que fomentan nuevas prácticas, ideas y sentimientos. Lazos que nos ayudan a cuidar el ambiente natural y las relaciones sociales de los cuales dependemos. Lazos que demuestran su efectividad al autonomizarnos como colectividad consciente y solidaria.

\section{REFERÊNCIAS}

HOLMGREN, David. Permaculture: Principles and Pathways Beyond Sustainability. Hepburn, Victoria: Holmgren Design Services, 2002, 286 p.

MA. Millenium Ecosystem Assessment. Ecosystems and Human Well-Being: Synthesis. Washington DC: Island Press, 2005, 137 p.

MOLLISON, Bill. Permaculture: A Designer’s Manual. Tasmania: Tagari, 1988, 573 p.

PIAGET, Jean. The language and the thought of the child. New York: Kegan Paul, 1926, 320 p.

WATSON, John B. Psychology as the behavorist views it. Psychological Review, n. 20, 1913, p. $158-177$.

FREIRE, Paulo. Pedagogia do Oprimido. Rio de Janeiro: Paz e Terra, 1970, 218 p.

SKINNER, Burrhus F. The Behavior of Organisms. An Experimental Analysis. New York: Appleton Century, 1938, 457 p. 
KOHLBERG, Lawrence. Essays on Moral Development, Vol. I: The Philosophy of Moral Development. San Francisco: Harper \& Row, 1981, 441 p.

VYGOTSKY, Levy. Educational Psychology. Traducción al inglés por Robert Silvermann. Florida: St. Lucie Press, 1992, 432 p. 